\title{
Identifying barriers to dysphagia assessment in primary care - a Canadian survey of primary care dietitians
}

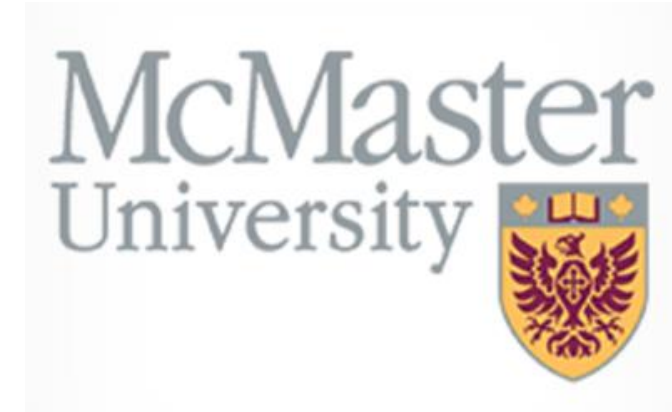

\author{
MacDonald-Werstuck M, MSc, RD, CDE ${ }^{1}$; \\ Steel C, MSc, RD2 \\ ${ }^{1}$ McMaster University, Hamilton, Ontario \\ ${ }^{2}$ Nestlé Health Science Canada
}

Nestlē

HealthScience
Introduction: Dysphagia or difficulty swallowing affects nearly $35 \%$ of older adults in the community and is a significant risk factor for malnutrition, aspiration and respiratory infections. Early intervention is important to minimize these risks. Yet, little is known about the dysphagia assessment practices of dietitians in the Canadian primary care setting.

Objectives: To learn more about dysphagia assessment practices of dietitians working in primary care in Canada.

Methods: A 17-question, on-line survey of dysphagia identification and assessment practices was developed with content and face validity confirmed through survey pilot and expert consultation. Registered dietitians practicing direct nutrition care in the primary care setting were invited to participate through Dietitians of Canada networks, newsletter advertisements and consenting provincial dietetic colleges. Descriptive statistics were used to analyze the survey.

Results: Of the 70 surveys completed, only $8 \%$ (6/70) reported non-instrumental, clinical swallowing assessment (CSA) were completed by the dietitian. The two most common barriers were lack of competency/skills required to complete a CSA (47/70) and not enough personnel/resources (18/70). Approximately $27 \%$ were either "not sure" or "did not believe" CSA fell within their scope of practice. Over 70\% (51/70) reported needing hands on dysphagia assessment training.
Conclusions: Dysphagia is prevalent in the primary care setting. Access to timely clinical swallowing assessments by dietitians could help expedite intervention and help minimize the consequences of unmanaged dysphagia. However, lack of competency/skills required to complete dysphagia assessments and uncertainty about dietitian scope of practice for dysphagia were commonly cited barriers to successful dysphagia assessment.

Significance to the field of dietetics: The high percentage of dietitians who felt they lacked the skill to conduct a dysphagia assessment is concerning. It appears additional training and education is needed to enable primary care dietitians to develop competency in dysphagia assessment and management.

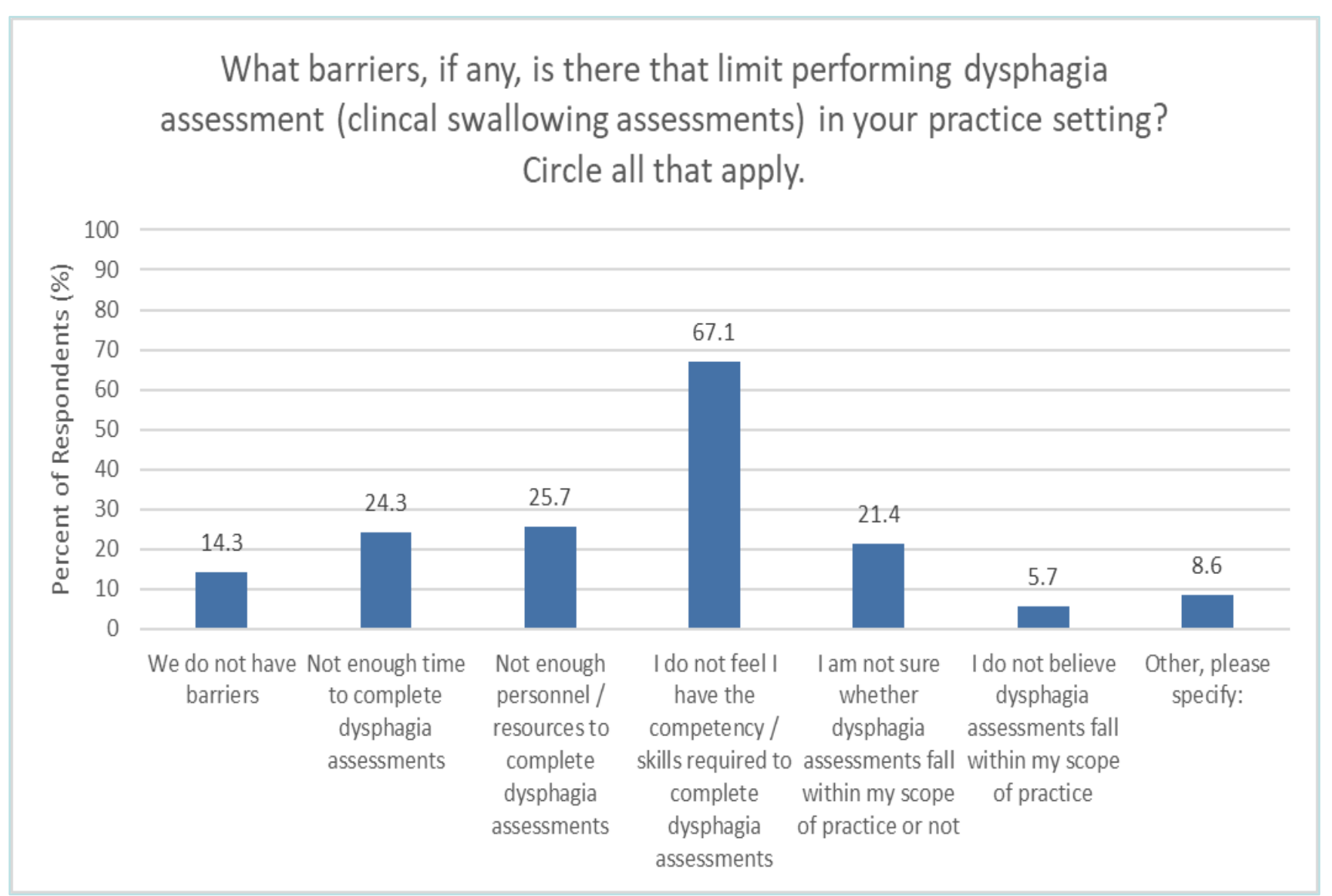

$67 \%$ Feel they do not have the competency/skills to complete dysphagia assessments ( $\mathrm{N}=47$ )

What tools and / or training, if any, do you need in order to provide

support for individuals with dysphagia in your practice setting?

Please check all that apply.

\begin{tabular}{|l|c|c|}
\hline I do not need tools and / or training & N & $\%$ \\
\hline Hands-on dysphagia screening training & 53 & 75.7 \\
\hline Hands-on dysphagia assessment training & 51 & 72.9 \\
\hline $\begin{array}{l}\text { Tools to share with your teams to increase the awareness and impact of } \\
\text { detecting dysphagia in primary care }\end{array}$ & 58 & 82.9 \\
\hline Validated screening tools to detect dysphagia in daily practice & 60 & 85.7 \\
\hline $\begin{array}{l}\text { Inter-professional clinical care pathways outlining the dysphagia screening, } \\
\text { and management process }\end{array}$ & 48 & 68.6 \\
\hline $\begin{array}{l}\text { Custom electronic medical record forms / tools to standardize dysphagia } \\
\text { screening }\end{array}$ & 42 & 60 \\
\hline Patient / caregiver resources to use for dysphagia nutrition counselling & 44 & 62.9 \\
\hline Other, please specify: & 1 & 1.4 \\
\hline
\end{tabular}

Need hands on dysphagia assessment training $(n=51)$ 